\title{
Dental Caries Status and Need for Dental Treatment of Pennsylvania Public School Children in Grades 1, 3, 9, and 11
}

\author{
Robert J. Weyant, DMD, DrPH; Michael Manz, DDS, MPH; Patricia Corby, DDS
}

\begin{abstract}
Objectives: This cross-sectional study was designed to determine the caries status and provide a general evaluation of the level of dental treatment need of Pennsylvania public school children in grades 1, 3, 9, and 11 on a statewide and regional basis. Methods: Between September 1998 and May 2000, caries status and treatment need were assessed using a school-based dental examination, performed on a representative sample $(n=6,040)$ of public school children in grades 1, 3, 9, and 11 (age range $=6$ to 21 years). Children's caries status in the primary and permanent dentition was assessed. Need for treatment was scored on a three-level categorical scale - no treatment need identified, routine treatment need, and urgent treatment need-and was based on the presence and severity of caries and other oral conditions. Population estimates of the prevalence of untreated dental caries, DMFT and dft scores, and treatment need were calculated by grade and geographically, using the six Pennsylvania health districts and the cities of Pittsburgh and Philadelphia. The inequality of caries distribution in the population was assessed for both permanent and primary caries using Lorenz curves and Gini coefficients. Results: Dental caries has remained highly prevalent among Pennsylvania's public school children. Caries levels varied considerably by health districts and city. Urgent treatment needs were significant and also varied by health district and city. Conclusions: Dental caries remains the most prevalent disease affecting Pennsylvania's schoolchildren. Caries status varies significantly by region of the state, suggesting that environmental, social, and demographic contextual factors may be important determinants of disease prevalence. [J Public Health Dent 2004;64(3):136-44]
\end{abstract}

Key Words: dental health surveys, dental caries, prevalence, needs assessment.

Dental caries is a common condition affecting children that can have lifetime health consequences if left untreated. Although caries prevalence has declined over the last 40 years, certain groups, defined by access to care, geography, and income, continue to remain at higher risk (1). Documenting caries status and treatment needs, especially at the state level, can provide important information that may help to motivate health policy and funding for prevention and treatment, and in targeting programs for those at risk for caries and other oral conditions. Additionally, understanding state and regional variations in caries can provide important information about the etiology of oral health disparities. State level surveys of oral health status, however, are rare in the literature and often do not employ representative sampling strategies. Representative surveys of caries prevalence have been conducted at the national level, with the two most recent surveys being the National Survey of Dental Caries in US Schoolchildren: 1986-87 (2) and the Third National Health and Nutrition Examination Survey (NHANES III) $(3,4)$. However, these surveys are not designed to allow for aggregation and interpretation of data at the state level. Consequently, representative caries data at the state level are, with a few notable exceptions, generally lacking. As a result, documentation of impor- tant state and regional variations in caries levels across the United States is often not available.

Between September 1, 1998, and May 30, 2000, the Pennsylvania Oral Health Needs Assessment (PaOHNA) was conducted, with 6,040 children screened in grades 1, 3, 9, and 11 (age range $=6$ to 21 years old) in a representative sample of Pennsylvania's public schools. The intent of the assessment was to provide baseline data to enable the Pennsylvania Department of Health to satisfy federal reporting requirements and to provide a basis for program planning. No prior statewide oral health assessment had ever been attempted in Pennsylvania.

This assessment was designed to allow for comparison of data on Pennsylvania children with national oral health data and to provide a measure of the status of Pennsylvania's children with regard to Healthy People 2000 (5) objectives for caries experience (objective 13.1) at aged 6-8 years and 15 years, and untreated caries (objective 13.2) prevalence at the same ages. In addition, these findings will serve as a baseline for estimating progress toward Healthy People 2010 objectives (6). Population estimates were desired overall for the state, and separately for the six Dental Health Districts and the cities of Pittsburgh and Philadelphia. This paper summarizes the study findings on caries experience and untreated caries, as well as the need for dental treatment.

\section{Methods \\ Sampling Strategy. This study was designed to provide a representative sample of Pennsylvania public school children in grades $1,3,9$, and 11 . The grades selected were the result of the need to meet Pennsylvania Depart- ment of Health reporting require-}

Send correspondence and reprint requests to Dr. Weyant, Room 346, Salk Hall, School of Dental Medicine, University of Pittsburgh, Pittsburgh, PA 15213. E-mail: rjw1@pitt.edu. Dr. Manz is with the University of Michigan, School of Dentistry, Ann Arbor. Dr. Corby is with the University of Pittsburgh, School of Dental Medicine, Department of Dental Public Health. This study was funded by a contract from the Commonwealth of Pennsylvania Department of Health. Manuscript received: $7 / 16 / 03$; returned to authors for revision: $9 / 12 / 03$; final version accepted for publication: $1 / 14 / 04$. 
ments, while also attempting to capture children of the ages listed in Healthy People 2000 objectives, all within the budgetary constraints. of the contract. The sample design for this survey was a random multistage PPS (probability proportional to size) selection of school districts from the public school system of Pennsylvania. The selection stages included, in sequence, the selection of school districts, schools within school districts, and children within schools. In selected classrooms, all eligible children were sampled. School districts were selected in the first stage using a list generated from Pennsylvania Department of Education data. Implicit stratification was employed by sorting the list on Dental Health District and school district enrollment size, and proceeding with a systematic PPS selection of school districts with a random start. The selection interval was determined based on the total school enrollment, so that 60 primary sampling units (PSUs), in this case school districts, would be selected with probability proportional to school district size. Philadelphia and Pittsburgh were oversized PSUs and were therefore treated as separate strata with a modified sampling plan described below. The geographic areas represented by the selected school districts are presented in Figure 1.

For selected school districts other than Philadelphia and Pittsburgh, lists were then prepared, one for grades 1 and 3 , and one for grades 9 and 11 . One school was selected with probability proportional to size from each list in each school district. In the final stage of selection, one class equivalents (approximately 25 children) were chosen for each index grade in each selected school either by random selection of a class or a method of random selection of 25 children from a survey index grade level.

The Philadelphia and Pittsburgh school districts were oversized PSUs and therefore sampled with certainty at the first stage of selection. Proportional representation for these school districts would require selection of eight PSU equivalents for Philadelphia and two PSU equivalents for Pittsburgh. However, to obtain more precise estimates of oral health for the two major cities of Pennsylvania, the decision was made to oversample these two districts and select 10 PSU equivalents for Philadelphia and five PSU equivalents for Pittsburgh. A probability proportional to size selection was again employed with implicit stratification geographically (systematic PPS selection of schools with a random start from a list with schools ordered geographically within the two city school districts), to obtain a welldistributed and representative sample of these two cities. For Philadelphia, schools were selected by school clusters (elementary schools tied in with high schools). In Pittsburgh, where elementary schools are not tied with specific high schools, separate lists and selections were made for elementary schools (for grades 1 and 3 ) and high schools (for grades 9 and 11). Once school clusters were selected in Philadelphia, an additional selection step was required to select a specific elementary school within the cluster. One class equivalents were selected at random for each index grade in each selected school.

Precision of population estimates in multistage cluster sample designs is affected more by the number of districts and schools that can be visited for assessments than by the number of children examined. To maximize the number of school district selections, one class equivalent from each grade level was included in any of the desired index grade groups selected. Resources allowed for a total of 60 districts, in addition to Pittsburgh and Philadelphia. With 60 PSUs plus the 15 PSU equivalents from Pittsburgh and Philadelphia, four index grade levels for each PSU, and one class equivalent of 25 students for each index grade level, the expected number of students to be selected for the survey was 7,500 . Incentives were used at the school level, including small free gifts, to encourage student participation in the survey. Strategies for seeking and obtaining consent varied by school based on advice and wishes of school staff, particularly the school nurse.

There were 13 district-level refusals among the 60 districts initially selected. Also, there were nine individual schools that refused within districts that had other participating schools. To ensure that the sample remained representative, replacements were chosen by random probability proportional to size selection of a district (or school) from the sampling interval that the refusing district (or school) was selected from. Due primarily to nonresponse at the child level within selected schools, the final sample size was 6,040 .

Given the complex cluster sample design employed for this survey, SUDAAN statistical software was used for analysis. Weights for analysis were based on sample design and nonresponse and were calculated as the inverse of the probability of being selected and examined in the survey, combining probabilities for all stages of sampling. The ultimate probability of a child being examined in the survey was a combination of the probabilities of school district selection, school selection, and selection and screening of the student within the school. The weights then approximate the number of children each examined child represents in the survey target population of Pennsylvania public school children in grades $1,3,9$, and 11.

Clinical Examination. Institutional Review Board clearance was obtained prior to initiation of this survey. The parent or guardian of each child selected for the study received a consent form approved by the University of Pittsburgh's Institutional Review Board. Consent was obtained prior to study participation. Strict infection control guidelines as recommended by the centers for Disease Control and Prevention (7) were followed and observed at all times.

The clinical assessment consisted of a clinical epidemiologic oral screening of each child. Clinical assessments of children were conducted in the schools by a licensed registered dental hygienists $(\mathrm{RDH})$, often accompanied by an assistant, using portable dental equipment.

Training and Calibration of Examiners. This study used five examiners in three teams. Each team included one or two RDHs who either conducted examinations alone or with an assistant/recorder. All $\mathrm{RDH}$ and recorders operated under the supervision of the principal investigator, a licensed dentist in Pennsylvania. Examiner training and calibration was conducted at the University of Pittsburgh by a team of epidemiologists from the University of Pittsburgh, the University of Michigan, and the Centers for Disease Control and Prevention (Atlanta, GA).

The training consisted of an initial 
familiarization of the examiners and recorders in all aspects of the clinical screening. After the examiners (RDHs) and the assistants were familiar with the clinical screening process, a formal calibration process was employed. This process consisted of repeated screening of 12 volunteer subjects until intra- and interexaminer repeatability of all clinical measures exceeded 90 percent agreement for all protocols. These training subjects had varying levels of disease and other conditions required to be assessed in the survey (e.g., sealants, malocclusion).

Repeated measures of several subjects were done approximately every other month during the course of this study to ensure that examiner calibration remained consistent. Interexaminer differences became significant enough to require a retraining intervention only once, during the summer hiatus between study years one and two.

Caries Protocol. The caries classification system employed in this study was a modification of the NHANES III classification system, which is based on the criteria proposed by Radike (8) and used in previous national surveys (9). The modifications included elimination of the use of an explorer and of the "extraction indicated" codes. The caries assessment was done visually with the aid of a mouth mirror, tongue blade, and artificial illumination (either headlamp or dental exam light). Examinations occurred with the child sitting in a regular (nondental) chair. Data were collected only at the tooth level. Each permanent tooth was classified as sound, filled, carious, or missing. Each primary tooth was classified as sound, filled, or carious. Missing primary teeth were not recorded due to difficulties in distinguishing between routine exfoliation and other causes of tooth loss. Using these criteria, the total number of decayed, filled, and missing permanent teeth and the total number of decayed and filled primary teeth were recorded for each child.

Teeth were classified as carious if they met the modified NHANES III criteria. To be classified as carious, a smooth tooth surface had to have visual evidence of cavitation (i.e., a break in the enamel surface). On the occlusal surface, teeth needed to have evidence of cavitation or undermined enamel, which included frosting or shadowing of the enamel. To be classified as filled, teeth needed to have evidence of either a permanent or temporary filling. Filled teeth that also contained

FIGURE 1

Map of Sampled School Districts

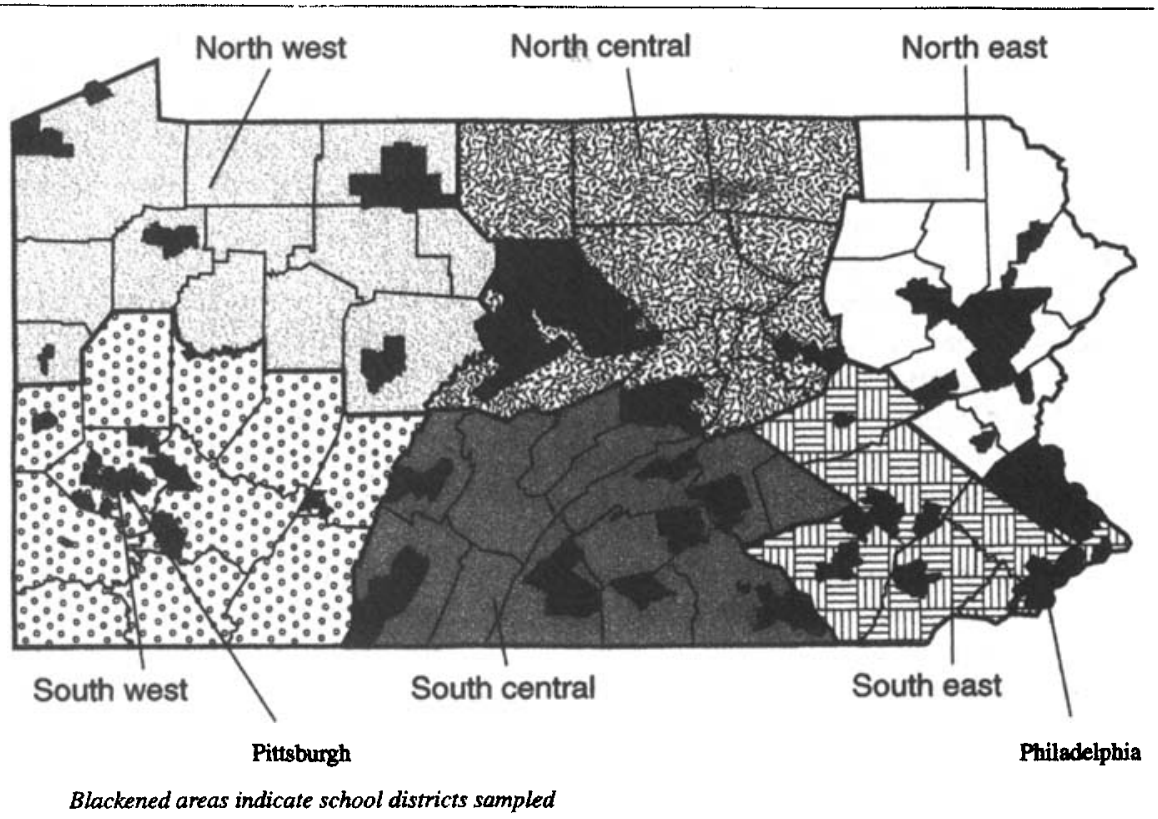

FIGURE 2

Mean Primary Decay (dft) Counts for First and Third Grade Children by Region Using Weighted Sample (Error bars represent $95 \%$ confidence interval of mean)

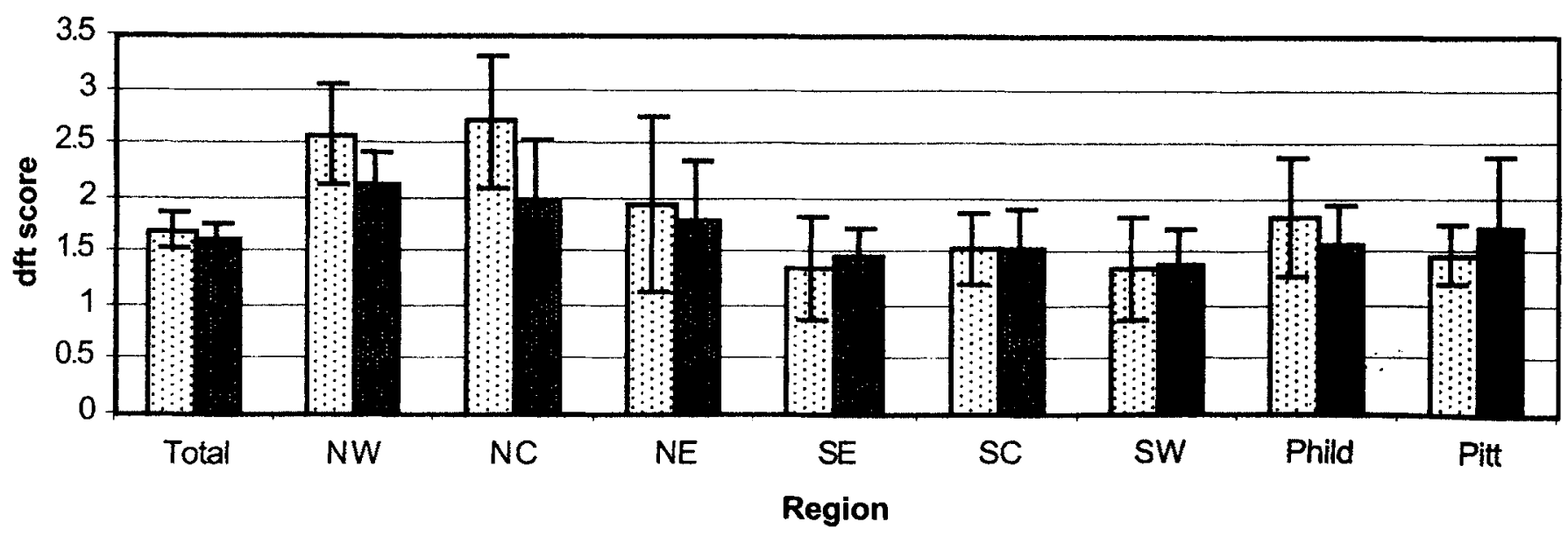


caries were classified as carious. The sound category was used for teeth with no evidence on any surface of treated or untreated caries and could include teeth with slight staining in an otherwise sound fissure. Permanent teeth were indicated as missing if they were determined by the examiner to be missing for caries-related reasons. This determination involved primarily excluding teeth lost due to trauma and extraction associated with orthodontic treatment. Third molars were not included in this study.

Other Measures. Sealants were detected visually by the examiner and recorded as present or absent. Malocclusion was assessed using a modification of the IOTN index (10). The modification involved essentially collapsing categories 2 and 3 of the IOTN into one "minor" malocclusion category and collapsing categories 4 and 5 into one "major" malocclusion category. The IOTN category 1 was scored as "no treatment" need. Tooth trauma was assessed visually and indicated as present when the examiner detected a tooth fracture, noncarious loss of tooth structure, or tooth displacement. Follow-up questions were asked of the children with evidence of trauma to confirm the finding and elicit etiology, particularly as it related to organized sports injuries.

Treatment Need Determination. After assessing all of the aspects of oral health status included in the PaOHNA screening, a final overall judgment was made as to whether children required dental treatment and whether treatment was required urgently or nonurgently. The urgent treatment need designation was used when any of the following conditions was present: caries deep into dentin, acute infection anywhere in the oral cavity, child report of significant pain, and suspicious oral soft tissue lesions requiring additional diagnostic followup (i.e., lesions that did not appear to be minor, self-limiting conditions such as aphthous ulcers, cheek bites, etc.). The nonurgent treatment need designation was given to any child with untreated caries insufficient to merit urgent treatment need, significant malocclusion, or periodontal inflammation. Each child's parent or guardian was notified of the treatment need status via a report sent home by the school nurse. It was made clear to all parents via the treatment need report form that the child had not received a comprehensive oral examination or a dental diagnosis and that the findings could not take the place of a routine dental examination from a licensed dentist. The report form also provided referral options to those families without a usual source of dental care, including local private practicing dentists, community health centers, dental school clinics, and other sources appropriate to each school district.

Data Entry, Processing, and Analytic Methods. All data were entered using EPI INFO (Centers for Disease Control and Prevention, Atlanta, GA) database software on laptop computers either via direct data entry at the time of the clinical examination or transferred later from paper collection forms. After checking data for accuracy, data were transferred to SAS software (SAS Institute, Cary, NC) for statistical analysis. In addition, SUDAAN (Research Triangle Institute, Research Triangle Park, NC) software was used for calculating final population estimates and standard errors. Descriptive statistics were calculated using sample design parameters and weights to account for the complex sampling design. The Gini coefficient was calculated using software available from the University of Sao Paulo, Brazil (11). The Gini coefficient compares the Lorenz curve to the line of perfect equality and is proportional to the area under the Lorenz curve. The Gini coefficient ranges from 0 to 1 , with larger numbers indicating greater inequality in the distribution of, in this case, caries.

\section{Results}

An oral health screening was completed on 6,040 Pennsylvania schoolchildren in grades $1,3,9$, and 11 . These children were selected from a total of 153 schools in 61 school districts. On average, approximately 40 children were examined in each sampled school. The sample represented 464,379 Pennsylvanian public school children. Details of the sampling and weighted sample are provided in Table 1. Figure 1 shows the health districts of the state and the geographic area covered by the sampled school districts.

Mean age in years by grade was 6.5 years $(95 \%$ confidence interval $[\mathrm{CI}] \pm 0.4)$ for grade $1 ; 8.6$ years $(95 \%$ $\mathrm{CI} \pm 0.6)$ for grade $3 ; 14.6$ years $(95 \%$
TABLE 1

Sample Size and Weighted Sample Size by Grade and Region

\begin{tabular}{|c|c|c|}
\hline & $\begin{array}{c}\text { Sample } \\
\text { Size }\end{array}$ & $\begin{array}{c}\text { Weighted } \\
\text { Size }\end{array}$ \\
\hline Total all grades & 6,040 & 464,379 \\
\hline Northwestern & 490 & 41,116 \\
\hline Northcentral & 383 & 28,998 \\
\hline Northeastern & 611 & 61,364 \\
\hline Southeastern & 1,428 & 113,096 \\
\hline Southcentral & 945 & 67,561 \\
\hline Southwestern & 841 & 76,928 \\
\hline Philadelphia & 881 & 63,232 \\
\hline Pittsburgh & 461 & 12,082 \\
\hline Total grade 1 & 1,808 & 125,865 \\
\hline Northwestern & 133 & 11,690 \\
\hline Northcentral & 88 & 6,747 \\
\hline Northeastern & 198 & 16,017 \\
\hline Southeastern & 431 & 29,912 \\
\hline Southcentral & 315 & 19,819 \\
\hline Southwestern & 250 & 19,750 \\
\hline Philadelphia & 247 & 18,436 \\
\hline Pittsburgh & 146 & 3,491 \\
\hline Total grade 3 & 1,768 & 129,009 \\
\hline Northwestern & 133 & 11,332 \\
\hline Northcentral & 89 & 7,752 \\
\hline Northeastern & 186 & 18,392 \\
\hline Southeastern & 432 & 31,002 \\
\hline Southcentral & 308 & 21,336 \\
\hline Southwestern & 258 & 19,899 \\
\hline Philadelphia & 244 & 16,019 \\
\hline Pittsburgh & 118 & 3,273 \\
\hline Total grade 9 & 1,350 & 114,653 \\
\hline Northwestern & 116 & 9,373 \\
\hline Northcentral & 103 & 7,339 \\
\hline Northeastern & 116 & 14,159 \\
\hline Southeastern & 330 & 29,086 \\
\hline Southcentral & 183 & 13,616 \\
\hline Southwestern & 171 & 20,347 \\
\hline Philadelphia & 214 & 17,568 \\
\hline Pittsburgh & 117 & 3,161 \\
\hline Total grade 11 & 1,114 & 94,851 \\
\hline Northwestern & 108 & 8,720 \\
\hline Northcentral & 103 & 7,158 \\
\hline Northeastern & 111 & 12,794 \\
\hline Southeastern & 235 & 23,094 \\
\hline Southcentral & 139 & 12,789 \\
\hline Southwestern & 162 & 16,930 \\
\hline Philadelphia & 176 & 11,208 \\
\hline Pittsburgh & 80 & 2,156 \\
\hline
\end{tabular}

$\mathrm{CI}+0.6)$ for grade 9; and 16.6 years (95\% CI \pm 0.6$)$ for grade 11 . Overall, the sample was 49 percent male, and 22 
TABLE 2

DMFT, Unfilled Permanent Tooth Decay, and Prevalence of Permanent Tooth Decay by Grade and Health District

\begin{tabular}{|c|c|c|c|c|c|c|}
\hline & \multirow[b]{2}{*}{$\begin{array}{c}\text { Mean } \\
\text { DMFT (SE) }\end{array}$} & \multirow[b]{2}{*}{$\begin{array}{c}\text { Mean } \\
\text { dft (SE) }\end{array}$} & \multicolumn{4}{|c|}{ Prevalence } \\
\hline & & & $\begin{array}{c}\text { Untreated } \\
\text { Decay }(\mathrm{SE}) \\
{[\mathrm{DdT}>01]}\end{array}$ & $\begin{array}{c}\text { Decay } \\
\text { Experience }(\mathrm{SE}) \\
{[\mathrm{DMFdft}>01]}\end{array}$ & $\begin{array}{c}\text { Any } \\
\text { Treatment Need } \\
\text { (SE) }\end{array}$ & $\begin{array}{l}\text { Urgent } \\
\text { Treatment } \\
\text { Need (SE) }\end{array}$ \\
\hline Total all grades & $1.03(0.05)$ & $0.93(0.05)$ & $21.43(1.14)$ & $51.45(1.23)$ & $27.27(1.43)$ & $4.66(0.49)$ \\
\hline Northwestern & $1.45(0.17)$ & $1.32(0.14)$ & $32.03(3.86)$ & $65.11(4.13)$ & $48.51(3.77)$ & $7.47(1.46)$ \\
\hline North central & $1.04(0.10)$ & $1.18(0.15)$ & $22.98(3.30)$ & $53.40(2.25)$ & $30.54(7.14)$ & $4.75(1.11)$ \\
\hline Northeastern & $1.14(0.18)$ & $1.06(0.15)$ & $20.47(2.86)$ & $50.85(4.67)$ & $24.04(2.88)$ & $5.16(1.98)$ \\
\hline Southeastern & $0.83(0.11)$ & $0.75(0.07)$ & $18.94(2.13)$ & $44.97(2.31)$ & $17.20(1.97)$ & $3.10(1.13)$ \\
\hline South central & $0.85(0.09)$ & $0.95(0.17)$ & $17.90(1.92)$ & $51.51(2.49)$ & $27.40(3.62)$ & $2.86(0.47)$ \\
\hline Southwestern & $1.07(0.11)$ & $0.74(0.11)$ & $18.19(4.02)$ & $52.14(3.52)$ & $32.44(4.65)$ & $2.53(0.87)$ \\
\hline Philadelphia & $1.16(0.11)$ & $0.95(0.15)$ & $25.79(3.30)$ & $51.97(2.44)$ & $23.71(3.99)$ & $9.72(1.39)$ \\
\hline Pittsburgh & $1.09(0.09)$ & $0.91(0.08)$ & $27.47(1.64)$ & $56.60(4.17)$ & $42.90(2.42)$ & $4.08(2.13)$ \\
\hline Total grade 1 & $0.14(0.02)$ & $1.71(0.09)$ & $27.51(1.59)$ & $46.34(1.80)$ & $29.26(1.53)$ & $6.18(0.74)$ \\
\hline Northwestern & $0.22(0.04)$ & $2.58(0.23)$ & $48.18(5.72)$ & $67.34(4.99)$ & $57.64(5.57)$ & $13.86(1.85)$ \\
\hline North central & $0.18(0.08)$ & $2.71(0.30)$ & $40.16(7.68)$ & $63.08(4.44)$ & $38.84(4.95)$ & $8.67(3.87)$ \\
\hline Northeastern & $0.16(0.05)$ & $1.96(0.41)$ & $27.50(6.18)$ & $48.14(7.83)$ & $26.56(4.46)$ & $6.63(2.97)$ \\
\hline Southeastern & $0.13(0.04)$ & $1.30(0.12)$ & $23.93(2.46)$ & $37.83(2.97)$ & $20.32(2.24)$ & $3.04(1.02)$ \\
\hline South central & $0.12(0.05)$ & $1.55(0.17)$ & $24.18(3.68)$ & $45.87(4.63)$ & $26.39(3.07)$ & $3.62(0.92)$ \\
\hline Southwestern & $0.12(0.03)$ & $1.38(0.24)$ & $20.73(4.18)$ & $44.08(4.55)$ & $32.61(4.37)$ & $4.61(2.16)$ \\
\hline Philadelphia & $0.13(0.05)$ & $1.84(0.27)$ & $26.32(3.16)$ & $42.07(3.31)$ & $22.74(4.23)$ & $9.70(2.24)$ \\
\hline Pittsburgh & $0.02(0.02)$ & $1.48(0.14)$ & $28.17(4.07)$ & $46.53(7.15)$ & $36.49(6.31)$ & $5.47(4.43)$ \\
\hline Total grade 3 & $0.35(0.03)$ & $1.63(0.07)$ & $27.26(1.67)$ & $52.58(1.69)$ & $34.39(2.20)$ & $5.16(0.74)$ \\
\hline Northwestern & $0.56(0.13)$ & $2.14(0.15)$ & $38.22(5.67)$ & $66.27(3.65)$ & $57.79(4.40)$ & $8.71(2.64)$ \\
\hline North central & $0.20(0.08)$ & $2.00(0.27)$ & $29.66(8.87)$ & $52.93(3.46)$ & $41.89(19.49)$ & $2.91(1.25)$ \\
\hline Northeastern & $0.42(0.09)$ & $1.81(0.28)$ & $28.24(5.65)$ & $54.89(6.84)$ & $27.97(6.62)$ & $7.83(3.19)$ \\
\hline Southeastern & $0.29(0.04)$ & $1.47(0.13)$ & $27.29(3.40)$ & $51.25(3.27)$ & $21.62(2.84)$ & $2.29(0.85)$ \\
\hline South central & $0.33(0.05)$ & $1.54(0.18)$ & $21.24(2.57)$ & $52.12(4.39)$ & $34.09(5.24)$ & $4.48(1.04)$ \\
\hline Southwestern & $0.29(0.07)$ & $1.41(0.17)$ & $23.69(3.95)$ & $45.57(4.19)$ & $49.92(4.02)$ & $4.04(1.16)$ \\
\hline Philadelphia & $0.39(0.11)$ & $1.58(0.19)$ & $29.71(4.86)$ & $51.75(3.51)$ & $23.08(5.81)$ & $8.94(3.16)$ \\
\hline Pittsburgh & $0.33(0.07)$ & $1.75(0.33)$ & $26.63(4.49)$ & $53.57(7.32)$ & $55.39(2.35)$ & $3.41(2.76)$ \\
\hline Total grade 9 & $1.74(0.11)$ & $0.02(0.01)$ & $13.87(1.37)$ & $50.50(2.03)$ & $22.03(2.01)$ & $2.87(0.49)$ \\
\hline Northwestern & $2.12(0.42)$ & $0.00(0.00)$ & $12.73(1.66)$ & $56.36(9.20)$ & $38.47(7.12)$ & $0.78(0.77)$ \\
\hline North central & $1.54(0.39)$ & $0.03(0.02)$ & $11.91(5.14)$ & $41.85(6.53)$ & $25.39(5.17)$ & $2.10(2.10)$ \\
\hline Northeastern & $1.81(0.41)$ & $0.01(0.01)$ & $13.50(3.96)$ & $42.68(6.62)$ & $19.42(5.55)$ & $2.44(1.26)$ \\
\hline Southeastern & $1.42(0.20)$ & $0.02(0.01)$ & $10.03(1.61)$ & $43.34(2.81)$ & $11.33(1.88)$ & $2.36(1.29)$ \\
\hline South central & $1.64(0.29)$ & $0.03(0.02)$ & $9.75(3.50)$ & $50.70(6.20)$ & $24.28(6.22)$ & $0.59(0.44)$ \\
\hline Southwestern & $1.86(0.32)$ & $0.04(0.02)$ & $15.32(4.69)$ & $57.98(5.88)$ & $25.39(6.66)$ & $0.76(0.50)$ \\
\hline Philadelphia & $2.01(0.19)$ & $0.01(0.01)$ & $21.15(4.12)$ & $58.00(4.08)$ & $22.44(4.65)$ & $9.67(1.57)$ \\
\hline Pittsburgh & $1.90(0.23)$ & $0.02(0.01)$ & $26.78(7.29)$ & $63.51(2.82)$ & $42.10(7.94)$ & $3.20(3.02)$ \\
\hline Total grade 11 & $2.30(0.11)$ & $0.02(0.01)$ & $14.58(1.72)$ & $57.84(2.13)$ & $21.31(2.16)$ & $4.11(0.95)$ \\
\hline Northwestern & $3.51(0.14)$ & $0.01(0.01)$ & $23.10(4.76)$ & $70.02(3.40)$ & $35.02(7.58)$ & $4.48(2.80)$ \\
\hline North central & $2.24(0.08)$ & $0.04(0.03)$ & $10.87(4.17)$ & $56.62(3.00)$ & $15.69(7.07)$ & $5.76(2.32)$ \\
\hline Northeastern & $2.65(0.30)$ & $0.00(0.00)$ & $8.20(2.38)$ & $57.46(7.01)$ & $20.36(3.96)$ & $2.49(1.75)$ \\
\hline Southeastern & $1.73(0.27)$ & $0.00(0.00)$ & $12.50(3.94)$ & $47.83(5.48)$ & $14.62(3.95)$ & $5.19(3.17)$ \\
\hline South central & $2.02(0.29)$ & $0.00(0.00)$ & $11.26(3.38)$ & $60.12(4.99)$ & $21.13(4.89)$ & $1.39(1.13)$ \\
\hline Southwestern & $2.13(0.22)$ & $0.04(0.01)$ & $12.22(5.55)$ & $62.25(4.20)$ & $20.20(6.99)$ & $0.47(0.46)$ \\
\hline Philadelphia & $2.60(0.22)$ & $0.08(0.05)$ & $26.58(4.92)$ & $59.12(5.06)$ & $28.22(5.83)$ & $10.96(2.63)$ \\
\hline Pittsburgh & $2.80(0.23)$ & $0.01(0.01)$ & $28.63(10.06)$ & $67.37(10.15)$ & $35.51(12.97)$ & $4.15(1.64)$ \\
\hline
\end{tabular}


FIGURE 3

Mean Permanent Decay (D2MFT) Counts for Ninth and 11th Grade Children by Region Using Weighted Sample (Error bars represent $95 \%$ confidence interval of mean)

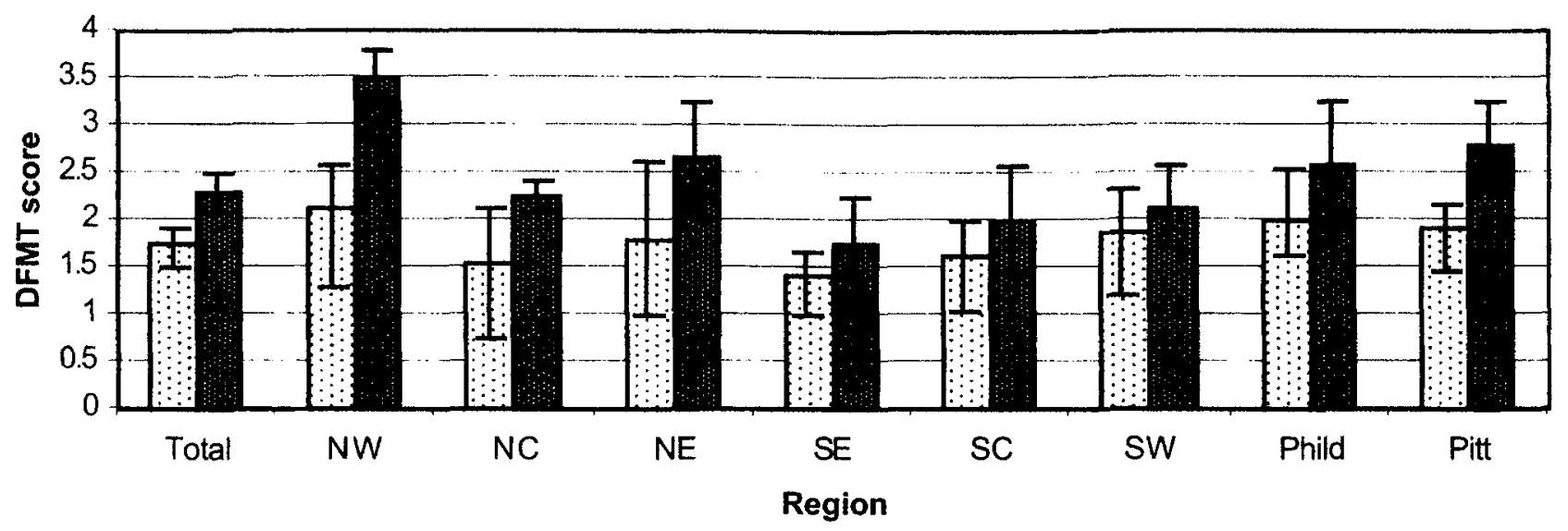

- Grade 9 - Grade 11

percent nonwhite.

Overall, dental caries was found to be highly prevalent in Pennsylvania's schoolchildren. Dental caries prevalence in the primary dentition (i.e., $\mathrm{dft}<0)$ was 45 percent $(95 \% \mathrm{CI} \pm 3.8 \%)$ for children in grade 1 and 48 percent $(95 \% \mathrm{CI} \pm 3.5 \%)$ for children in grade 3 . Details of the primary caries prevalence by grade and health district are provided in Table 2. Figure 2 shows graphically the variation in primary caries prevalence across the health districts. Primary caries prevalence among first grade students ranged from 37 percent in the southeast district of the state to 64 percent in the northwest district, a 1.7-fold difference in prevalence rates. Among third grade children the lowest prevalence was found in the southwest $(41 \%)$ and the highest again in the northwest $(62 \%)$, a 1.5 -fold difference. It can be seen in Figure 2 that the covariation between primary caries levels in first and third grades was high within the health districts, with the northwest and northcentral districts having the highest prevalence in both first and third grades, and the southeast and southwest districts having the lowest prevalence for both grades.

The extent of caries in the primary dentition statewide, measured by mean dft scores, was 1.71 (95\% CI \pm .18$)$ for first grade children and 1.63 (95\% $\mathrm{CI}+14$ ) for third grade children (Table 2). Regional differences in mean dft scores between health districts were again pronounced, with over a two-

TABLE 3

Summary Statistics for All Pennsylvania Children Using Weighted Sample

\begin{tabular}{|c|c|c|c|c|}
\hline & \multicolumn{4}{|c|}{ Grade (SE) } \\
\hline & 1 & 3 & 9 & 11 \\
\hline $\begin{array}{l}\text { Mean dft (for children } \\
\text { with } \mathrm{dft}>0 \text { ) }\end{array}$ & $3.83(0.10)$ & $3.41(0.07)$ & $1.50(0.20)$ & $1.66(0.26)$ \\
\hline $\begin{array}{l}\text { Mean DMFT (for } \\
\text { children with } \\
\text { DMFT>0) }\end{array}$ & $1.91(0.14)$ & $1.93(0.07)$ & $3.50(0.13)$ & $3.98(0.15)$ \\
\hline $\begin{array}{l}\text { Prevalence of } \\
\text { Dental sealants (sealants }>0 \text { ) }\end{array}$ & $8.7(0.96)$ & $26.1(1.50)$ & $24.3(1.78)$ & $28.2(2.52)$ \\
\hline Missing permanent teeth & $0.27(0.14)$ & $0.40(0.24)$ & $2.13(0.43)$ & $4.17(0.68)$ \\
\hline DT & $4.13(0.64)$ & $6.59(0.93)$ & $13.34(1.40)$ & $14.39(1.71)$ \\
\hline $\mathrm{dt}$ & $26.53(1.59)$ & $24.61(1.56)$ & $0.60(0.24)$ & $0.56(0.26)$ \\
\hline
\end{tabular}

fold difference in dft scores across health districts among first graders, and a 1.5-fold difference among third grade students. As with the prevalence results, the northwest and northcentral districts had the highest mean $\mathrm{dft}$ scores, and the southeast and southwest districts had the lowest. In fact, the northern three health districts generally had considerably higher mean dft counts than the southern districts or the cities of Pittsburgh and Philadelphia.

Caries experience data for the permanent dentition are provided in Table 2 and in Figure 3. Overall caries prevalence rates for the permanent dentition (DMFT $>0$ ) were 50 percent $(95 \% \mathrm{Cl} \pm 4.1)$ for ninth grade students and 58 percent $(95 \% \mathrm{CI} \pm 4.3)$ for 11 th grade students. District variations were evident, with approximately 1.5fold differences in the caries prevalence from the lowest to the highest districts for both grades.

Table 3 also shows the prevalence of total unfilled carious lesions was nearly 14 percent for children in both ninth and 11th grades. Prevalence of unfilled lesions varied across health districts of the state by a factor of 2.8 in ninth grade children and 3.5 in 11th grade children. The districts with the highest unfilled caries rates were the urban areas of Philadelphia and Pittsburgh, where the percent of children with unfilled carious lesions exceeded 20 percent in both cities and approached 30 percent in the 11th grade children in Pittsburgh. 
DMFT rates averaged $1.74( \pm .22)$ in ninth grade children and $2.30( \pm .22)$ in 11 th grade children. Among 11 th grade students, a twofold difference in DMFT rates existed across health districts, with the highest score of 3.51 $( \pm .28)$ in the northwest, and the lowest score of $1.73( \pm .54)$ in the southeast. Once again, higher caries levels were found across the northern three health districts, but with higher rates in Pittsburgh and Philadelphia, as well.
We also calculated prevalence rates for 6-8-year-old and 15-year-old children to facilitate comparisons with Healthy People objectives. There were 2,624 children 6 to 8 years of age and they had a caries prevalence of 48 percent $(95 \% \mathrm{CI} \pm 3.5 \%)$. The prevalence of untreated caries in these children was 27 percent $(95 \% \mathrm{CI} \pm 3.2 \%)$. There were 661 children 15 years of age, with a caries prevalence of 49 percent $( \pm 5.8 \%)$ and a prevalence of untreated caries of

FIGURE 4

Lorenz Curves of Cumulative Caries Distribution for Total Caries (DMFT, dft)* and Unfilled Caries (DT, dt) in First and 11th Grade Children Using Weighted Sample

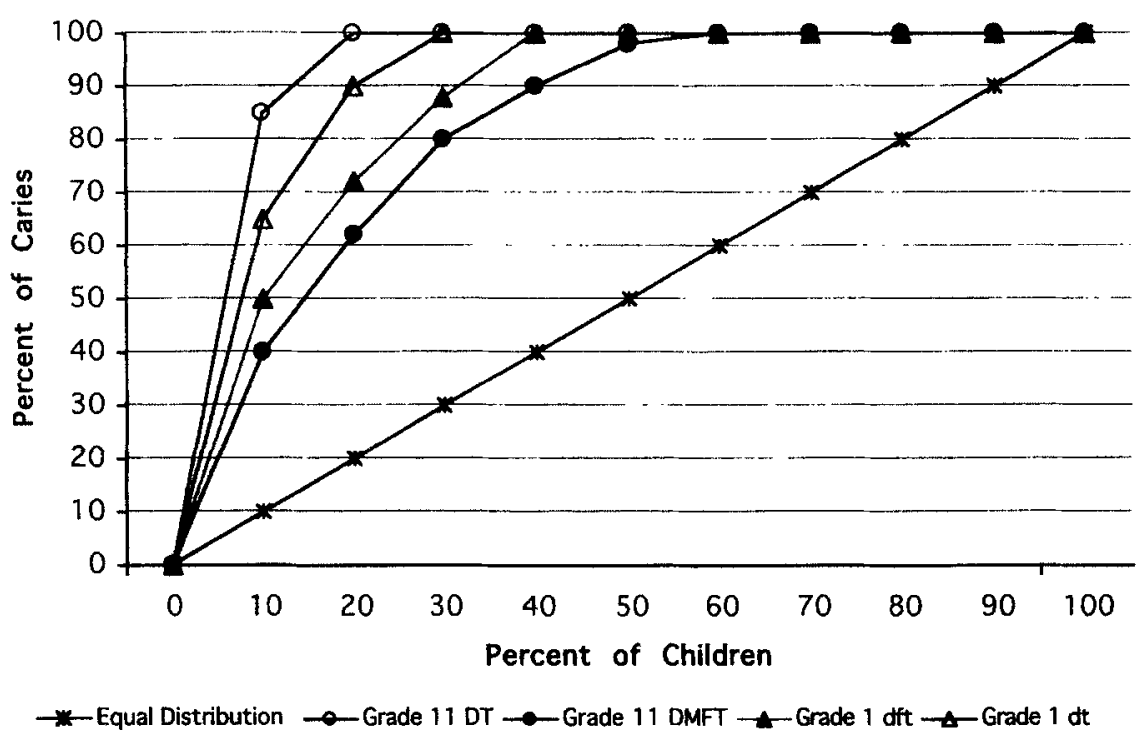

14 percent $(95 \% \mathrm{CI} \pm 4.4 \%)$.

Figure 4 shows graphically, using Lorenz curves, the cumulative distribution of total caries experience (primary and permanent combined) for first and 11th grade children using the weighted estimates for all children in Pennsylvania. Although not presented in the figure, the curves for the third and ninth grade children were intermediate between the first and 11 th grade curves. Also shown in Figure 4 is the line of perfect equality. The difference between the equal distribution and the actual is a measure of the inequality in caries distribution. For example, using Figure 4 it can be estimated that among Pennsylvania's first grade children, 80 percent of the carious teeth were found in about 25 percent of the children, and among 11th grade children, 80 percent of the carious teeth were found in about 30 percent of the children.

The Gini coefficient, which provides a measure of the inequality in caries distribution, was calculated for overall caries (DMFT+dft) and unfilled caries $(\mathrm{DT}+\mathrm{dt})$. The Gini coefficient for overall caries was 0.711 for first grade children, 0.665 for third grade children, 0.690 for ninth grade children, and 0.649 for 11 th grade children. The Gini coefficient for unfilled caries was 0.837 for first grade children, 0.833 for third grade children, 0.909 for ninth grade children, and 0.911 for 11 th grade children.

The need for dental treatment is pre-

FIGURE 5

Percent of Subjects with Any Treatment Need and Urgent Treatment Need by Region (All Grades) Using Weighted Sample (Error bars represent $95 \%$ confidence interval of mean)

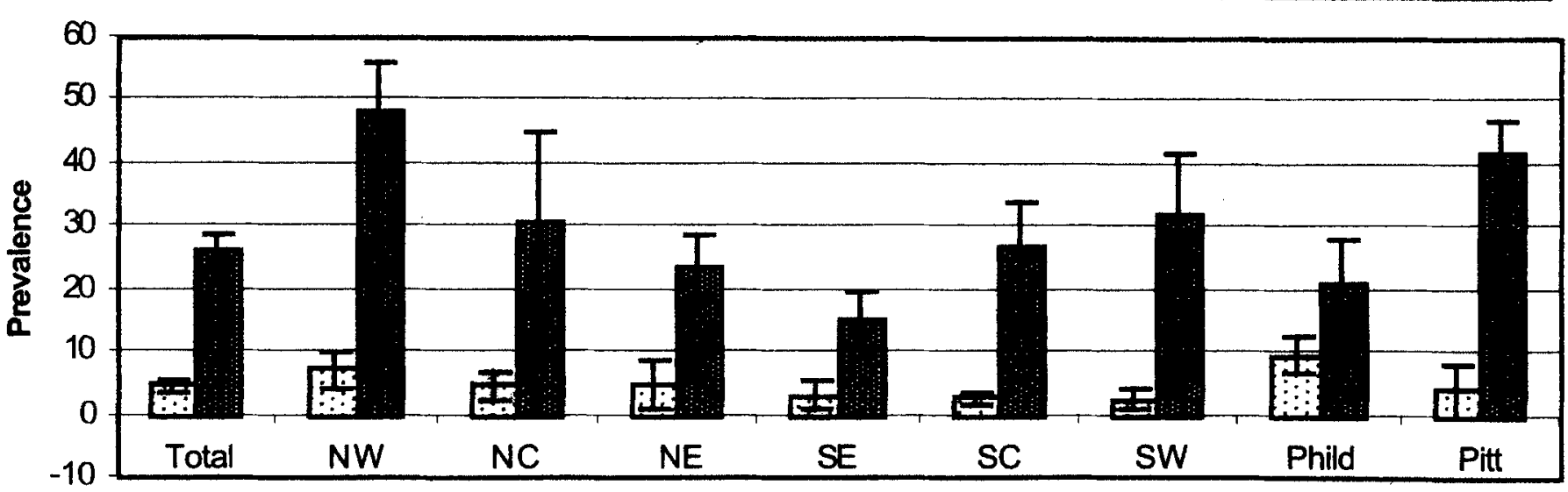

Region 
sented in Figure 5. Overall, 4.7 percent of children had "urgent" treatment needs, and 27 percent of children had unmet "nonurgent" treatment needs. Philadelphia is noteworthy for its high levels of urgent treatment need, approaching 10 percent of children at all four grades examined. Overall treatment need results (urgent and nonurgent) were highest in the northwest district followed by Pittsburgh. These levels of need were over two times higher than the need found in the southeast district and Philadelphia.

Finally, statewide results for all children for overall caries (primary plus permanent caries), extent of caries among children with at least one carious lesion, and dental sealant prevalence are provided in Table 3 . Notable among these findings is the sealant prevalence of roughly one-quarter of third, ninth, and 11th graders. For those students with at least one carious lesion, there was a steady increase in DMFT rate by grade, ending with a DMFT of nearly 4 among the 11th graders.

\section{Discussion}

Results of this study are similar to US national figures from NHANES III (4). For example, the US national average for caries-free children in the age group 5-9 years was 50.3 percent (4). This corresponds closely with Pennsylvania's grades 1 and 3 children, who were 53.7 percent and 47.4 percent caries free, respectively. Similarly, the dft score for the 5-9-year-old children from the NHANES III study was 1.9 , with 40.4 percent of this score coming from the " $\mathrm{d}$ " component. This study found a dft score of 1.7 for first grade, with 46 percent coming from the " $\mathrm{d}$ " component, and 1.6 for third grade, with 37 percent from the " $d$ " component. As in NHIANES III, the percent of the dft index represented by the " $d$ " component decreased with increasing age.

Results for the permanent dentition from NHANES III data for the entire US show that 32.7 percent of 12-17year-old children were caries free. In Pennsylvania, 50.2 percent of public school children in grade 9 and 42.3 percent of children in grade 11 were caries free in the permanent dentition. The mean DMFT score for the 12-17year-old children in NHANES III was 2.8. Mean DMFT scores in Pennsylvania were 1.7 for ninth grade children and 2.3 for 11th grade children. The " $\mathrm{D}$ " component of the DMFT index for 12-17-year-old children in the NHANES III findings was 17.3 percent, compared to 17.8 percent for ninth graders and 15.3 percent for 11 th graders in Pennsylvania.

Thus, on all measures of caries prevalence and severity, Pennsylvania public school children seemed to fare slightly better than national averages from NHANES III findings. This might be explained in at least three ways. First, it could be that Pennsylvania children are now, and have been since the NHANES III study, less affected by caries than the US population as a whole. On the other hand, nearly 10 years have elapsed between the two studies, and perhaps caries rates have declined nationally. These data may simply reflect that phenomenon as manifested in the Pennsylvania children. Of course, it is also possible that the samples are not comparable due to underlying differences in study design or in the application of the diagnostic criteria, despite study efforts to obtain comparable representative data.

This study, it should be remembered, did not use an explorer or radiographs and had no access to prior treatment records. However, research shows that visual inspection provides high sensitivity and specificity for caries diagnosis and is often the only choice for many epidemiologic studies $(12,13)$. As is typical, field examination conditions were not ideal, especially with regard to intraoral lighting and chair position. Our use of regular classroom chairs and headlamps was dictated by the extensive amount of travel necessitated by our design. Thus, there is always a concern that certain conditions such as interproximal lesions, tooth-colored restorations, and clear sealants could be missed during a screening exam (14). As a result, our caries and sealant estimates may be lower than what truly exists.

One concern of the Pennsylvania State Department of Health was the status of state children with regard to national objectives. Our findings indicate that Healthy People 2000 objectives for caries (Objective 13.1:35\%) or unfilled caries (Objective 13.2: 20\%) were not met in Pennsylvania children aged 6-8 years, whereas Healthy People 2000 objectives have already been met in Pennsylvania children 15 years of age both for caries experience $(60 \%)$ and untreated caries (15\%).

Of particular interest is the significant regional variations found in disease rates. In general, the northwest district, and to some degree the northcentral and northeast districts, had higher disease levels when compared with the southern districts. The northwest district had, in general, higher levels of primary tooth caries, DMFT rates, untreated caries prevalence, and treatment needs. This study did not attempt to determine underlying causes for regional differences; however, several speculations can be made. The northern area of Pennsylvania is populated primarily by individuals of European ancestry and is well known to be a very rural, relatively poor region, with few dentists. The terrain ranges from hilly to mountainous, with many geographic barriers to travel. Cities in the northern regions are limited to Erie in the west, and Wilkes Barre and Scranton in the east. Erie, which from a population perspective dominates the northwestern district, only began to fluoridate its water supply in December 2002. It is impossible to determine in this study whether any of these factors are related to the higher disease rates found in the northern tier; nevertheless, it provides fertile ground for the development of hypotheses about the potential role of geography, culture, and access to care as risk factors for oral disease.

Another important finding is the high prevalence of untreated permanent tooth caries in ninth and 11th grade children in Philadelphia and Pittsburgh. The majority of our study participants in both cities were from poorer neighborhoods and primarily of African decent. Once again, the study permits only speculation about the nature of these results, but difficulties with access or poor dental attendance behaviors are strongly suggested. Continuing research should investigate the similarities and differences in factors associated with poorer oral health in the urban and rural areas and better oral health in suburban areas. It should be remembered that not only is caries not uniformly distributed among communities, but caries also varies greatly among individuals within communities. In fact, relatively few children have the majority of all 
carious lesions and the majority of treatment needs. This is now commonly referred to as the disparity in oral health status, and determining its root causes and developing interventions to reduce its effect are important issues before public health policy makers and providers.

It may be useful to other oral health researchers and oral health policy planners to contrast this study with another that used a different approach, such as the recently reported New Hampshire survey (15). The design employed in the New Hampshire survey allowed for a relatively lowcost $(\$ 5,000)$ and rapid approach to assessing oral health status, by focusing only on obtaining state-level prevalence estimates of a single (third) grade and by using the Basic Screening Survey Techniques (16). As a result, New Hampshire examined 410 students in 26 schools and was able to report on the percentage of children with dental caries experience, untreated caries, presence of sealants on permanent molars, and urgency of care.

Comparing results for third grade students from the two studies demonstrates some similar findings and some dramatic differences in oral health status. For example, caries prevalence (i.e., DMFTdt $>0)(52 \%$ in New Hampshire vs $53 \%$ in Pennsylvania); urgent treatment need $15.1 \%$ in New Hampshire and 5.2\% in Pennsylvania); and to some degree untreated caries prevalence (i.e., DdT $>0)(22 \%$ in New Hampshire vs $27 \%$ in Pennsylvania) were comparable. On the other hand, sealed molars $(46 \%$ in New Hampshire vs $26 \%$ in Pennsylvania), and nonurgent treatment needs (25\% in New Hampshire vs 34\% in Pennsylvania) were quite different. Thus, Pennsylvania third graders appear to have more untreated caries, fewer sealants, and somewhat more nonurgent treatment needs,although total caries experience is similar.

The Pennsylvania survey used an elaborate study design, requiring two years to complete the examinations and costing approximately $\$ 400,000$. Although the study reported here is limited to only caries and treatment urgency results, the Pennsylvania survey design resulted in a considerable amount of data being collected, in- cluding interviews with parents, questionnaires of health behaviors of the surveyed children, and more detailed clinical assessments. Pennsylvania's use of grades 1, 3, 9, and 11 permits perhaps some sense of caries disease levels through different age cohorts. The Pennsylvania sample design also allowed for estimates of health status at a region level, thereby allowing evaluation of geographic subpopulation variation within the state and consequently allowing for program targeting within the state (e.g. sealants and fluoride initiatives).

This study also implicitly stratified using school district enrollment size as a proxy to ensure proportional representation, allowing for comparison of oral health outcomes by urban/rural status and race/ethnicity. Finally, by collecting not only presence/absence, but also counts of untreated carious, filled, and missing teeth, it is possible to differentiate among children with different dental disease levels. Individual counts for untreated carious teeth and teeth with caries experience allows for the ability to create Lorenz curves to evaluate the disparity in dental disease among children. Ideally this extra information will be an important aid in program planning, allowing for the efficient use of funds to make the largest impact on dental diseases in Pennsylvania schoolchildren.

The Gini coefficients highlight a final concern, the continuing disparity in access to dental care. The Gini coefficients for untreated disease ranging from 0.833 to 0.911 indicate a serious disparity in need for and access to adequate dental treatment. The Lorenz curve shows that among 11th grade children, 90 percent of the untreated lesions are found in 10 percent of the children. Identifying these high-risk children and remedying the root cause of their inability to receive treatment for caries should be a prime concern of policy planners and the dental profession in Pennsylvania.

\section{References}

1. Edelstein BL. Disparities in oral health and access to care: findings of national surveys. Ambulatory Pediatrics 2002;2: 141-7.

2. National Institute of Dental Research. Oral health of United States children: the National Survey of Dental Caries in US Schoolchildren: 1986-1987. Bethesda, MD: US Department of Health and Hu- man Services, National Institutes of Health, National Institute of Dental Research, Epidemiology and Oral Disease Prevention Program, 1989; NIH pub no 89-2247.

3. Brown LJ, Kaste LM, Selwitz RH, Furman LJ. Dental caries and sealant usage in US children, 1988-1991: selected findings from the Third National Health and Nutrition Examination Survey. J Am Dent Assoc 1996;127:335-43.

4. Kaste LM, Selwitz RH, Oldakowski RJ, Brunelle JA, Winn DM, Brown LJ. Coronal caries in the primary and permanent dentition of children and adolescents 117 years of age: United States, 1988-1991. J Dent Res 1996;75(Spec Iss):631-41.

5. US Department of Health and Human Services. Healthy People 2000: national health promotion and disease prevention objectives. Full report, with commentary. Washington, DC: US Department of Health and Human Services, Public Health Service, 1990; DHHS pub no (PHS) 91-50212.

6. US Department of Health and Human Services. Healthy People 2010. 2nd ed. With understanding and improving health and objectives for improving health. 2 vols. Washington, DC: Government Printing Office, 2000.

7. Centers for Disease Control and Prevention. Recommended infection-control practices for dentistry. MMWR Morbid Mortal Wkly Rep 1993;41(RR-8):1-12.

8. Radike AW. Criteria for diagnosis of dental caries. In: cariostatic agents. Chicago: American Dental Association, 1972:87-8.

9. National Institute of Dental Research. Oral health surveys of the National Institute of Dental Research: diagnostic criteria and procedures. Bethesda, MD: National Institute of Dental Research, Epidemiology and Oral Disease Prevention Program, 1991; NIH pub no 01-2870.

10. Brook PH, Shaw WC. The development of an index for orthodontic treatment priority. Eur J Orthodont 1989;11:309-32.

11. Gini calculation for carious distribution; http://www.fo.usp.br/arquivos/Gini calculation_for_caries_distribution.zip accessed 8/5/03).

12. al-Sehaibany F, White G, Rainey JT. The use of caries detector dye in diagnosis of occlusal carious lesions. J Clin Pediatr Dent 1996;20:293-8.

13. Ketley CE. Holt RD. Visual and radiographic diagnosis of occlusal caries in first permanent molars and in second primary molars. Br Dent J 1993;174:364-70.

14. Beltran ED, Malvitz DM, Eklund SA. Validity of two methods for assessing oral health status of populations. J Public Health Dent 1997;57:206-14.

15. Centers for Disease Control and Prevention. Oral Health Survey of Third Grade Students-New Hampshire, 2001. MMWR Morbid Mortal Wkly Rep 2002; 51:259-60.

16. Association of State and Territorial Dental Directors. Basic screening survey: an approach to monitoring community oral health. Columbus, OH: Association of State and Territorial Dental Directors, 1999. 